\title{
Genotoxicity testing of Persicariae Rhizoma (Persicaria tinctoria H. Gross) aqueous extracts
}

\author{
WON HO LEE ${ }^{1 *}$, SEONG HUN CHOI ${ }^{1 *}$, SU JIN KANG ${ }^{2}$, CHANG HYUN SONG $^{1}$, \\ SOO JIN PARK ${ }^{1}$, YOUNG JOON LEE ${ }^{2}$ and SAE KWANG KU ${ }^{1}$ \\ Departments of ${ }^{1}$ Anatomy and Histology and ${ }^{2}$ Preventive Medicine, College of Korean Medicine, \\ Daegu Haany University, Gyeongsan, Gyeongbuk 38610, Republic of Korea
}

Received February 1, 2015; Accepted April 5, 2016

DOI: $10.3892 / \mathrm{etm} .2016 .3273$

\begin{abstract}
Persicariae Rhizoma (PR) has been used as an anti-inflammatory and detoxification agent in Korea, and contains the biologically active dyes purple indirubin and blue indigo. Despite synthetic indigo showing genotoxic potential, thorough studies have not been carried out on the genotoxicity of PR. The potential genotoxicity of an aqueous extract of PR containing indigo $(0.043 \%)$ and indirubin $(0.009 \%)$ was evaluated using a standard battery of tests for safety assessment. The PR extract did not induce any genotoxic effects under the conditions of this study. The results of a reverse mutation assay in four Salmonella typhimurium strains and one Escherichia coli strain indicated that PR extract did not increase the frequency of revertant colonies in any strain, regardless of whether S9 mix was present or not. The PR extract also did not increase chromosomal aberrations in the presence or absence of S9 mix. Although slight signs of diarrhea were restrictedly detected in the mice treated with $2,000 \mathrm{mg} / \mathrm{kg}$ PR extract, no noteworthy changes in the frequency of micronucleated polychromatic erythrocytes were observed at doses $\leq 2,000 \mathrm{mg} / \mathrm{kg}$ in a bone marrow micronucleus test. These results indicate the potential safety of the PR extract, particularly if it is consumed in small amounts compared with the quantities used in the genotoxicity tests.
\end{abstract}

Correspondence to: Professor Young Joon Lee, Department of Preventive Medicine, College of Korean Medicine, Daegu Haany University, 1 Haanydae-ro, Gyeongsan, Gyeongbuk 38610, Republic of Korea

E-mail: gksxntk@dhu.ac.kr

Professor Sae Kwang Ku, Department of Anatomy and Histology, College of Korean Medicine, Daegu Haany University, 1 Haanydae-ro, Gyeongsan, Gyeongbuk 38610, Republic of Korea E-mail: gucci200@hanmail.net

${ }^{*}$ Contributed equally

Key words: Persicariae Rhizoma, Persicaria tinctoria H. Gross, genotoxicity, reverse mutation assay, chromosomal aberration assay, mouse micronucleus assay

\section{Introduction}

Genotoxic substances are specific chemical or physical agents, including viruses and hormones, that can damage the genetic information within a cell, thereby inducing mutations or cancer, and genotoxicity refers to the capacity of a chemical or physical substance to damage genetic information. Although genotoxicity differs from mutagenicity, the terms are often used confusedly; all mutagens are genotoxic, however, not all genotoxic substances are mutagenic. Mutagens induce direct or indirect damage to DNA that leads to mutations, which are permanent and heritable changes that can affect somatic cells to be transmitted onto future generations (1). When DNA damage occurs, a DNA damage response, including cell cycle arrest, DNA repair and apoptosis, is induced in cells to suppress the induction of mutation; however, this DNA damage may not always be processed resulting in mutagenesis $(2,3)$.

When evaluating genotoxic substances, scientists test for DNA damage in cells with exposure to the toxic agents. This DNA damage can be categorized as single- and double-strand breaks, loss of excision repair, cross-linking, the formation of alkali-labile sites, point mutations, and structural and numerical chromosomal aberrations (4). The loss of integrity of the genetic information can lead to cancer. To evaluate the potential of chemicals to cause DNA damage, various methods have been developed. Among these, the Ames assay, in vitro and in vivo toxicology tests and the Comet assay are widely used $(5,6)$. The deleterious effect of the genotoxic substance is DNA damage induced by interaction with the DNA sequence and structure. On occasion, lesions within DNA under oxidative stress conditions can lead to mutation, and the accumulation of mutations can contribute to the development of cancer (7).

Natural materials have received special attention as a potential source of bioactive components in the pharmaceutical industry (8). Although materials such as herbs, medicinal plants and crude drug substances obtained from them are generally accepted as being safe (9), it is important to evaluate natural substances for mutagenicity. Evidence suggests that certain types of foods may cause toxic, genotoxic or carcinogenic hazards for humans (10). Contaminated foods are known to show harmful effects, and certain food additives may have mutagenic and/or carcinogenic potential (11). In addition, the cooking process may generate carcinogenic compounds (12), 
and certain foods with natural constituents may show mutagenic and/or carcinogenic toxicity (13).

Persicariae Rhizoma (PR) is dried stem parts of Persicaria tinctoria H. Gross (Polygonaceae), and has been traditionally used as an anti-inflammatory and detoxification agent in Korea (14). PR contains two biologically active anti-inflammatory and antioxidative dyes, namely purple indirubin and blue indigo (15). Indirubin, a 3,2'-bisindole isomer of indigo, was first identified as the active ingredient of a traditional Chinese medicine preparation, Danggui Longhui Wan, which is used to treat various chronic diseases (16). Indirubin derivatives exhibit strong anti-inflammatory and anti-leukemic activities (17). A previous study showed that indirubin is a potent inhibitor of a wide range of kinases, but, in particular, it strongly suppresses the activation of cyclin-dependent kinases (18). Herbal extracts containing indigo or their derivatives have also exhibited potent antibacterial (19), antitumor (20), anti-inflammatory (21) and antioxidant (22) activities. In a previous study, it was revealed that natural indigo products showed no mutagenicity but all synthetic indigo products showed enzyme-mediated mutagenicity (23). It has also been demonstrated that the mutagenic effect of purified synthetic indigo and natural indigo may be attributed to one or more structurally related contaminants, and the metabolic activation of these promutagenic factors appears to involve glutathione (24). In addition, mutagenic effects of synthetic indigo of technical grade or $98 \%$ purity have been observed in the Ames test (25), and some synthetic colorants are harmful when ingested in large amounts (13). As mammalian intestinal microorganisms are able to cleave azo bonds and lead to the generation of degradation products such as aromatic amines that are potentially mutagenic and carcinogenic, the use of azo dyes has been limited (26). However, no preclinical studies of PR extract containing the natural dyes indigo and indirubin, have been performed, to the best of our knowledge, not even a basic rodent single-dose toxicity test. Moreover, the demand for PR extract has increased for use in foodstuffs and functional food materials, as well as for its nutritive value and as a natural dye. Therefore, the present study was conducted to test the genotoxicity of an aqueous extract of PR containing indigo and indirubin using a standard battery of tests, including the bacterial reverse mutation assay, the chromosomal aberration assay and the mouse micronucleus assay, as used to test other materials in our previous studies $(27,28)$.

\section{Materials and methods}

Chemicals, culture medium and $S 9$ activation system. Fetal bovine serum (FBS) was obtained from Invitrogen (Thermo Fisher Scientific, Inc., Waltham, MA, USA). Cyclophosphamide (CPA), ethylmethanesulfonate (EMS), sodium azide (SA), 4-nitroquinolone-1-oxide (4NQO), 9-aminoacridine (9-AA), 2-aminoanthracene (2-AA), indigo and indirubin standards, dimethylsulfoxide (DMSO), formic acid and acetonitrile were supplied by Sigma-Aldrich (St. Louis, MO, USA). Bacto agar was obtained from Difco (BD Biosciences, Franklin Lakes, NJ, USA). Cell culture-grade water used in the chromosomal aberration assay and the reverse mutation assay, culture medium, antibiotics and L-glutamine were purchased from Invitrogen (Thermo Fisher Scientific, Inc.).
The S9 mix was purchased from Molecular Toxicology, Inc. (Boone, NC, USA). For the reverse mutation assay, the S9 mix (per $1 \mathrm{ml}$ ) was composed of $\mathrm{MgCl}_{2} \cdot 6 \mathrm{H}_{2} \mathrm{O}(8 \mu \mathrm{mol}), \mathrm{KCl}$ (33 $\mu \mathrm{mol})$, glucose 6 -phosphate $(5 \mu \mathrm{mol})$, nicotinamide adenine dinucleotide phosphate (NADPH; $4 \mu \mathrm{mol}$ ), nicotinamide adenine dinucleotide (NADH; $4 \mu \mathrm{mol}$ ), sodium phosphate buffer $(100 \mu \mathrm{mol}, \mathrm{pH} 7.4)$ and $\mathrm{S} 9(50 \mu \mathrm{l})$. The $\mathrm{S} 9$ mix was used at $0.5 \mathrm{ml} /$ plate, and the activities were determined using 2-AA. In the chromosomal aberration test, the S9 mix (per $1 \mathrm{ml})$ was composed of $\mathrm{MgCl}_{2} \cdot 6 \mathrm{H}_{2} \mathrm{O}(8 \mu \mathrm{mol}), \mathrm{KCl}(33 \mu \mathrm{mol})$, G-6-P $(5 \mu \mathrm{mol})$, NADPH $(4 \mu \mathrm{mol})$, NADH $(4 \mu \mathrm{mol})$, sodium phosphate buffer (0.1 M, pH 7.4) and $\mathrm{S} 9(0.3 \mathrm{ml})$. The $\mathrm{S} 9$ mix was prepared just prior to use and maintained in an ice bath. The S9 mix was used at $0.5 \mathrm{ml} / 5 \mathrm{ml} / \mathrm{T}-25$ flask, and the effectiveness of the $S 9$ mix was identified by its ability to activate CPA to induce a mutagenic effect.

\section{Test substance}

Preparation of aqueous extract. Aqueous PR extract (yield, $12.00 \%$ ) as a greenish brown powder was prepared using a rotary vacuum evaporator (Eyela N-1110; Tokyo Rikakikai Co., Ltd., Tokyo, Japan) and programmable freeze dryer (FDB-5503; Operon, Gimpo, South Korea). The extract was prepared from dried stem parts of Persicaria tinctoria H. Gross (Polygonaceae) collected from the South Korean province of Yeongcheon, which were purchased from Omniherb (Yeongcheon, South Korea) after checking the morphology under a microscope. Voucher specimens (code. CD2012Ku) were kept in the herbarium of the Medical Research Center for Globalization of Herbal Formulation, Daegu Haany University (Gyeongsan, South Korea). Next, $200 \mathrm{~g}$ herbs were boiled at $80^{\circ} \mathrm{C}$ in $2 \mathrm{~L}$ distilled water for $3 \mathrm{~h}$, then evaporated and lyophilized. As a result, $24 \mathrm{~g}$ extract was acquired (yield=12\%). All test materials were stored in a refrigerator at $-20^{\circ} \mathrm{C}$ to protect them from light and degeneration until use.

Measurement of indigo and indirubin content in the $P R$ extract. Standard solutions containing $1 \mu \mathrm{g} / \mathrm{ml}$ concentrations of indigo and indirubin in DMSO were prepared and diluted with 1:1 DMSO:acetonitrile mixtures to concentrations of 1, 5 and $10 \mathrm{ng} / \mathrm{ml}$. Standard stock solutions and working solutions were stored at $4^{\circ} \mathrm{C}$. For preparation of the sample, samples of PR extract were weighed, and dissolved in 1:1 DMSO and acetonitrile mixtures. The samples were then sonicated for $1 \mathrm{~h}$ at room temperature. Prior to high performance liquid chromatographic system (HPLC) analysis, the sample preparations were filtered through a $0.45-\mu \mathrm{m}$ membrane filter. A Waters Alliance HPLC system (Waters Corporation, Milford, MA, USA), equipped with a Waters 2489 UV/Visible detector was used for analysis. An Empower Data System and YMC-Pack Pro C-18 column (1.7 $\mu \mathrm{m}, 2.1 \times 100 \mathrm{~mm}$; both Waters Corporation) were used for recording the output signal of the detector and for separation, respectively. The mobile phase consisted of $0.1 \%$ aqueous formic acid and $0.1 \%$ formic acid in acetonitrile. The flow rate in the gradient elution system was $1.0 \mathrm{ml} / \mathrm{min}$, the injection volume was $10 \mu \mathrm{l}$, the UV detection wavelength was $540 \mathrm{~nm}$ and the column was maintained at room temperature.

Reverse mutation assay.

The bacterial reverse mutation assay was conducted according to standard procedures $(29,30)$. Salmonella typhimurium 
(TA98, TA100, TA1535 and TA1537) and Escherichia coli WP2uvrA were used to determine whether reverse mutations were induced at histidine and tryptophan loci, respectively.

Materials. All strains were obtained from Molecular Toxicology Inc., and confirmed for retention of their characteristic phenotypic markers at the time of use, as previously described (31). Tester strains were inoculated into $25 \mathrm{ml} 2.5 \%$ Oxoid nutrient broth no. 2 and incubated at $37^{\circ} \mathrm{C}$ for $10 \mathrm{~h}$ in a 200-rpm shaking incubator (LabTech LSI-3016R; Daihan Labtech Co., Ltd., Namyangju, Korea). Minimal glucose agar plates were prepared with $1.5 \%$ Bacto agar, Vogel-Bonner medium $\mathrm{E}$ and $2 \%$ glucose/liter, and dispensed into $25-\mathrm{ml}$ $100 \times 15 \mathrm{~mm}$ Petri dishes. For the E. coli strain, $0.25 \mathrm{ml} / 10.1 \%$ tryptophan solution was added to the agar plates.

Treatment. Sterile distilled water was used to prepare PR extract solution and was also used as a negative control to compare with the PR extract. PR extract solution was diluted with sterile distilled water to prepare stock solutions for each treatment without $(-\mathrm{S})$ or with $(+\mathrm{S})$ the $\mathrm{S} 9$ mix. 2-AA, 9-AA and 4NQO solutions were prepared in DMSO. SA solutions were prepared in sterilized distilled water. Following autoclaving, $2 \mathrm{ml}$ top agar was dispensed into $12 \mathrm{x} 75-\mathrm{mm}$ tubes at $45^{\circ} \mathrm{C}$. PR extract $(0.1 \mathrm{ml}), \mathrm{S} 9 \mathrm{mix}$ (or sodium-phosphate buffer, $\mathrm{pH} 7.4 ; 0.5 \mathrm{ml})$ and bacterial culture $(0.1 \mathrm{ml})$ were then added and mixed gently for $2-3 \mathrm{sec}$. This mixture was then poured onto a minimal glucose agar plate. In addition, the PR extract test solution and S9 mix, without bacterial culture, were plated to confirm sterility. When the top agar had hardened, the plates were turned upside down and incubated at $37^{\circ} \mathrm{C}$ for $\sim 48 \mathrm{~h}$. Revertants were then counted and the formation of a background lawn and other abnormalities were observed. The PR extract was assayed in quadruplicate per concentration.

Judgment. Results are shown as the mean number of colonies \pm standard deviation (SD) of quadruplicate plates. After checking for contamination, the formation of a background lawn and other abnormalities were analyzed. If the ratio number of colonies on a treated plate/number of colonies on a negative control plate was $<0.5$, the test material was judged to have an antibacterial effect. A result was considered positive if the frequency of revertant colonies per plate in at least one strain was concentration-dependently increased over the range tested and/or there was a reproducible increase at one or more concentrations regardless of S9 activation.

\section{Chromosomal aberration assay.}

Assays were conducted using methods described previously (32) with slight modifications.

Materials. Chinese hamster lung (CHL) cells (33) were supplied by the Division of Genetic Toxicology, Department of Toxicology, Korea Food and Drug Administration (KFDA; Seoul, South Korea). Cells were grown in reconstituted minimum essential medium supplemented with sodium bicarbonate (2.2 g), L-glutamine (292 mg), streptomycin sulfate $(100 \mu \mathrm{g} / \mathrm{ml})$, sodium penicillin $\mathrm{G}\left(1 \times 10^{5}\right.$ units $)$ and FBS $(10 \% \mathrm{v} / \mathrm{v})$. Cells were maintained in incubator with a humidified atmosphere of $5 \% \mathrm{CO}_{2}$ in air at $37^{\circ} \mathrm{C}$. Rapidly growing cultures were separated with trypsin. Cells $\left(4 \times 10^{4}\right)$ were seeded in culture flasks $\left(25-\mathrm{cm}^{2}\right)$ in $5 \mathrm{ml}$ medium and incubated for 3 days.
Treatment. In this assay, cells were directly treated with test (PR extract) and positive control materials (CPA and EMS). Cells were divided into series I, II and III groups. The PR extract was added following a $1 \mathrm{~h}$ incubation in $4.0 \mathrm{ml}$ medium for series I (+S9) and $4.5 \mathrm{ml}$ medium for series II and III (-S9). Cultures of series I and II were treated with PR extract for $6 \mathrm{~h}$, the treatment mixture was then removed, and the cells were washed once with $\mathrm{Ca}^{2+}$ - and $\mathrm{Mg}^{2+}$-free Dulbecco's phosphate-buffered saline (DPBS) followed by further incubation in $5 \mathrm{ml}$ fresh medium until harvesting. Cultures of series III were cultured with PR extract for $24 \mathrm{~h}$ and the washing procedure was omitted. At $\sim 22 \mathrm{~h}$ after treatment, colchicine $(1 \mu \mathrm{M})$ was treated to each culture, and the cultures were incubated for an additional $2 \mathrm{~h}$. Mitotic cells were isolated by shaking gently. Following centrifugation at $150 \mathrm{x} \mathrm{g}$ for $5 \mathrm{~min}$, the supernatant was removed and cell pellets were resuspended in $5 \mathrm{ml} 0.075 \mathrm{M} \mathrm{KCl}$ solution. After $10 \mathrm{~min}$ at room temperature, fixative solution (methanol:glacial acetic acid, 3:1 v/v) was rapidly added and the suspension was kept at $4^{\circ} \mathrm{C}$ for $20 \mathrm{~min}$. The fixed cell suspension was dropped onto glass slides and then air-dried followed by staining with Giemsa (3\% in Sorensen buffer, $\mathrm{pH}$ 6.8).

Judgment. The criteria for the identification of chromosomal aberrations were those of Evans (34). The structural aberrations were divided into two broad types: Chromatid and chromosome gaps, chromatid type deletions and exchanges; and chromosome type deletions and exchanges. Each slide was scanned systematically, and each set of metaphases was examined under x1,000 magnification. To identify aberrations, 100 metaphases on each slide that had a chromosome count of between 23 and 27 were examined. After recording each type of aberration, the number of aberrant metaphases (showing one or more aberrations, including/excluding gaps) and total aberrations (including/excluding gaps) were calculated. The results are shown as mean aberrant metaphases excluding gaps per 100 metaphases from quadruple flasks/dose.

\section{In vivo mouse micronucleus assay}

Animals and husbandry. A total of 62 male specific pathogen-free CrljOri:CD1 (ICR) mice (6 weeks old and body weight in the range of 31-34 g upon receipt; Orient Bio Inc., Seungnam, Korea) were obtained, and five groups of 10 mice each (total 50 mice) were selected based on the body weights at 9 days after acclimatization [mean \pm standard deviation (SD), $36.16 \pm 1.98 \mathrm{~g}$; range 33.6-40.7 g]. Animals were maintained at five per polycarbonate cage in a controlled room of $50-55 \%$ humidity and $20-25^{\circ} \mathrm{C}$ temperature. The light:dark cycle was 12 h:12 h, and standard rodent chow (Samyang Feed, Seoul, Korea) and water were supplied ad libitum. All animals were maintained in accordance with international regulations for the usage and welfare of laboratory animals, and approved by the Institutional Animal Care and Use Committee of Daegu Haany University (Approval No. DHU2014-017).

Treatment. Mice were treated by oral gavage for 2 consecutive days with $500,1,000$ or $2,000 \mathrm{mg} / \mathrm{kg} /$ day PR extract in a volume of $10 \mathrm{ml} / \mathrm{kg}$, dissolved in distilled water as vehicle or with an equal volume of vehicle (for vehicle control mice), with $\sim 24 \mathrm{~h}$ between doses. As there are no available toxicological data for PR extract administered orally to female and male mice, the highest dosage used in the present study was selected 

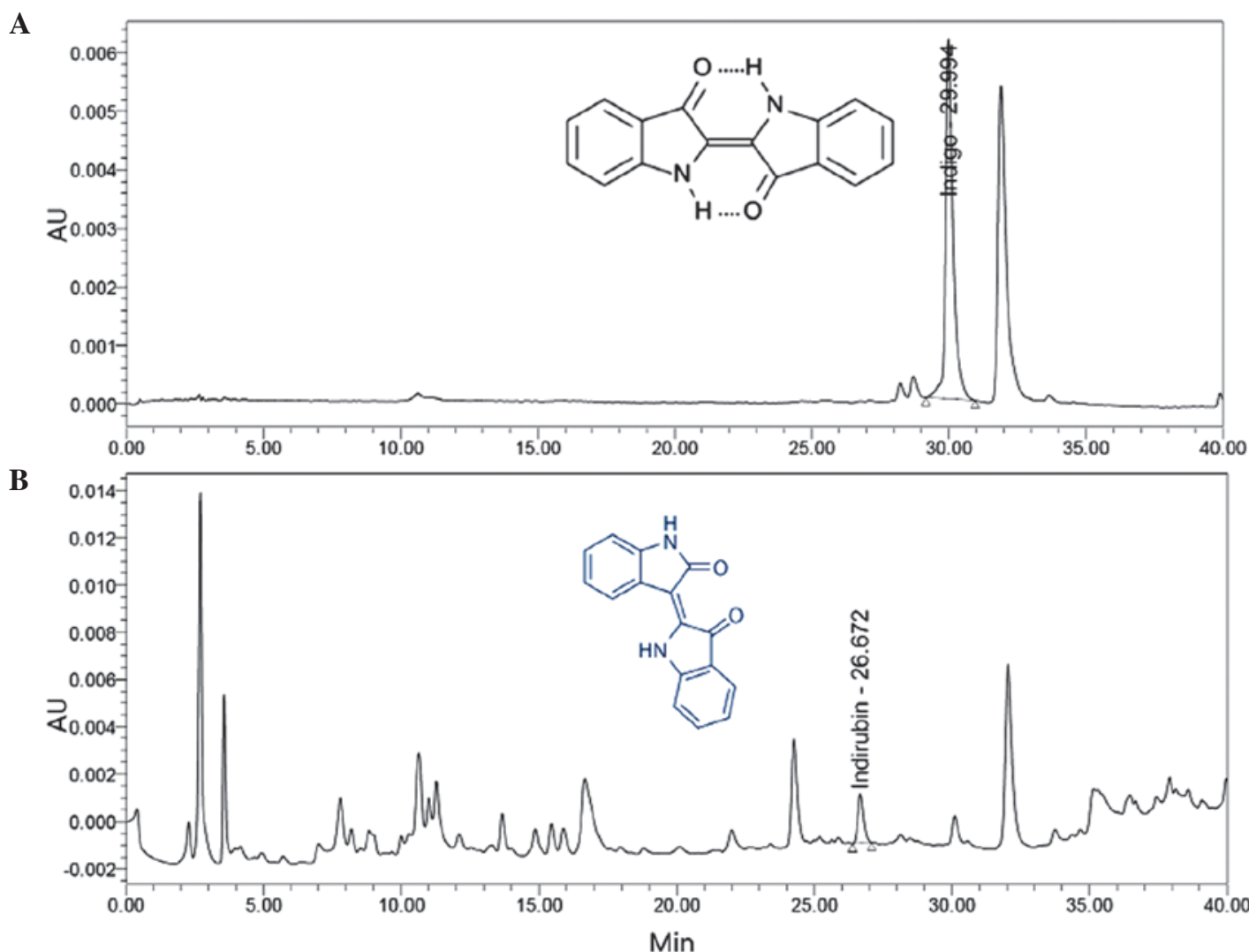

Figure 1. HPLC chromatograms of (A) indigo and (B) indirubin in PR extract. Determination of indigo and indirubin content in the PR extract was established by use of a HPLC system, and the results indicated that the lyophilized aqueous extract of PR contained $0.043 \%$ indigo and $0.009 \%$ indirubin. HPLC, high performance liquid chromatography; PR, Persicariae Rhizoma; AU, absorbance unit.

as $2,000 \mathrm{mg} / \mathrm{kg}$, the limited dosage for rodents (35), and 1,000 and $500 \mathrm{mg} / \mathrm{kg}$ were selected for administration to the middle and lower dosage groups according to the recommendations of the KFDA. A similar group was treated once with the positive control (70 mg/kg of CPA) at $24 \mathrm{~h}$ prior to sacrifice.

Observation of clinical signs. According to the functional observational battery test, all abnormalities were checked at least twice a day (36). If any abnormal clinical signs were detected, they were subdivided into three degrees according to the status of animals: $3+$ severe, 2+ moderate and 1+ slight (37).

Changes of body weights. Body weights were measured at 1 day before administration, immediately prior to treatments and at sacrifice ( $24 \mathrm{~h}$ after the end of the second treatment).

Bone marrow preparation. Animals were asphyxiated with $\mathrm{CO}_{2}$, and gross necropsy was performed in all surviving animals at $24 \mathrm{~h}$ after the end of the second treatment, and bilateral femurs were separated. Bone marrow preparations were made according to the method of Schmid (38). Bone marrow cells were collected from the femur in $3 \mathrm{ml}$ inactivated FBS, centrifuged at $300 \mathrm{x} \mathrm{g}$ for $10 \mathrm{~min}$ in room temperature and smeared onto a slide. Preparations were then dried, and dipped into absolute methanol for 10-20 min. Fixed slides were serially stained using May-Grünwald stock (3 min; Sigma-Aldrich), May-Grünwald stock and tap water (1:1) diluted solution (2 min) and Giemsa and tap water (1:6) diluted solution (10 min), respectively.

Judgment. Slides were randomly observed through a microscope (Eclipse 80i, Nikon Corporation, Tokyo, Japan) at x400 magnification and examined blindly by two experts.
Micronuclei were morphologically identified according to the criteria defined by Schmid (39). Micronuclei, which appeared as small round or oval-shaped bodies, ranging in size from $\sim 1 / 5$ to $1 / 20$ of the diameter of a polychromatic erythrocyte (PCE) were counted and recorded. In total, 2,000 PCEs per animal were examined to determine the number of micronuclei. Cytotoxicity was evaluated by counting the frequency of PCEs and normochromatic erythrocytes (NCEs) in at least the first 500 erythrocytes from each animal. Furthermore, in cases where all of the PCE/[PCE + normochromatic erythrocyte $(\mathrm{NCE})]$ ratios were $>0.20$, the experimental results were accepted (40).

Statistical analysis. Quantitative data are presented as means \pm standard deviations. One-way analysis of variance (ANOVA) or the Kruskal-Wallis H test for multiple comparisons were conducted. When a significant difference was detected in a statistical hypothesis test, the Scheffe's test or Mann-Whitney $\mathrm{U}$ test with Bonferroni correction was conducted to determine the significantly different pairs of groups. Statistical analyses were performed using SPSS for Windows (version 14.0K; SPSS, Inc., Chicago, IL, USA), and $\mathrm{P}<0.05$ was considered to indicate a statistically significant difference.

\section{Results}

Indigo and indirubin content in the PR extract. Determination of the quantities of indigo and indirubin in the PR extract was established by use of HPLC. The indigo and indirubin contents 
Table I. Results of preliminary range-finding tests in the bacterial reverse mutation assay.

\begin{tabular}{|c|c|c|c|c|c|c|}
\hline \multirow[b]{2}{*}{ Treatment } & \multirow[b]{2}{*}{ Dose $(\mu \mathrm{g} / \mathrm{plate})$} & \multicolumn{5}{|c|}{ Colonies/plate, mean (factor) ${ }^{\mathrm{a}}$} \\
\hline & & TA98 & TA100 & TA1535 & TA1537 & WP2uvrA \\
\hline \multicolumn{7}{|l|}{ Without S9 } \\
\hline Vehicle control $^{\mathrm{b}}$ & & $29(1.00)$ & $127(1.00)$ & $14(1.00)$ & $11(1.00)$ & $21(1.00)$ \\
\hline \multirow[t]{7}{*}{ PR extract } & 0.05 & $27(0.93)$ & $119(0.94)$ & $15(1.07)$ & $8(0.73)$ & $19(0.90)$ \\
\hline & 0.5 & $26(0.90)$ & $132(1.04)$ & $12(0.86)$ & $9(0.82)$ & $20(0.95)$ \\
\hline & 5 & $30(1.03)$ & $125(0.98)$ & $13(0.93)$ & $10(0.91)$ & $21(1.00)$ \\
\hline & 50 & $29(1.00)$ & $106(0.83)$ & $12(0.86)$ & $11(1.00)$ & $17(0.81)$ \\
\hline & 500 & $23(0.79)$ & $98(0.77)$ & $9(0.64)$ & $7(0.64)$ & $16(0.76)$ \\
\hline & 1,000 & $10(0.34)$ & $51(0.40)$ & $5(0.36)$ & $5(0.45)$ & $9(0.43)$ \\
\hline & 5,000 & $8(0.28)$ & $38(0.30)$ & $3(0.21)$ & $3(0.27)$ & $4(0.19)$ \\
\hline Sodium azide & 0.5 & & $398(3.13)$ & $483(34.50)$ & & \\
\hline 4-Nitroquinolone-1-oxide & 0.5 & $282(9.72)$ & & & & $132(6.29)$ \\
\hline 9-Aminoacridine & 50 & & & & $295(26.82)$ & \\
\hline \multicolumn{7}{|l|}{ With S9 } \\
\hline Vehicle control $^{\mathrm{b}}$ & & $38(1.00)$ & $119(1.00)$ & $9(1.00)$ & $17(1.00)$ & $17(1.00)$ \\
\hline \multirow[t]{7}{*}{ PR extract } & 0.05 & $36(0.95)$ & $121(1.02)$ & $7(0.78)$ & $16(0.94)$ & $16(0.94)$ \\
\hline & 0.5 & $40(1.05)$ & $117(0.98)$ & $9(1.00)$ & $18(1.06)$ & $14(0.82)$ \\
\hline & 5 & $32(1.84)$ & $108(0.91)$ & $10(1.11)$ & $17(1.00)$ & $13(0.76)$ \\
\hline & 50 & $35(0.92)$ & $105(0.88)$ & $8(0.89)$ & $15(0.88)$ & $18(1.06)$ \\
\hline & 500 & $30(0.79)$ & $93(0.78)$ & $6(0.67)$ & $11(0.65)$ & $15(0.88)$ \\
\hline & 1,000 & $15(0.39)$ & $42(0.35)$ & $3(0.33)$ & $6(0.35)$ & $7(0.41)$ \\
\hline & 5,000 & $7(0.18)$ & $32(0.27)$ & $2(0.22)$ & $4(0.24)$ & $4(0.24)$ \\
\hline \multirow[t]{3}{*}{ 2-Aminoanthracene } & 0.4 & $406(11.28)$ & $252(2.08)$ & & & \\
\hline & 2 & & & $327(46.71)$ & $351(21.94)$ & \\
\hline & 4 & & & & & $223(13.94)$ \\
\hline
\end{tabular}

${ }^{\mathrm{a}}$ Factor is the number of colonies of the treated plate/number of colonies of the negative control plate. ${ }^{\mathrm{b}}$ Vehicle control, sterile distilled water. PR, Persicariae Rhizoma.

of the extract were calculated from the calibration curve of the standards. The results indicated that the lyophilized aqueous extract of PR contained $0.043 \%$ indigo and $0.009 \%$ indirubin (Fig. 1).

Reverse mutation assay. The mutagenicity of the PR extract in bacteria was assessed up to a maximal dose of $1,000 \mu \mathrm{g} /$ plate, because PR extract exhibited antibacterial activity at 5,000 and $2,500 \mu \mathrm{g} /$ plate in all five test strains of the preliminary test (Table I). All strains showed normal growth, and the test material was freely soluble at all doses evaluated in the absence and presence of S9. The revertant frequencies of all PR extract doses in all tester strains were not changed, regardless of S9 activation, compared with those in the vehicle control cultures. All four positive control agents that were tested exhibited significant $(\mathrm{P}<0.05)$ increases in revertant frequencies of tested strains (Table II).

Chromosomal aberration assay. In the chromosomal aberration assay, the highest concentration of PR extract tested was $5,000 \mu \mathrm{g} / \mathrm{ml}$ since the calculated relative cell count for $5,000 \mu \mathrm{g} / \mathrm{ml}$ was $>89 \%$ in the preliminary experiments (Table III). There were no differences in structural and numerical chromosomal aberrations between all doses of PR extract in all three series of treatments (I, II and III) regardless of the presence or absence of the metabolic activator S9 when compared with those in the vehicle control. The two positive control agents tested in this study showed significant $(\mathrm{P}<0.05)$ increases in structural and numerical chromosomal aberrations (Table IV).

In vivo mouse micronucleus assay. No PR extract or CPA treatment-related unscheduled mortalities or changes in body weight were detected. All of the five experimental groups tested in the present study were subjected to bone marrow cell harvesting or blood sampling at $24 \mathrm{~h}$ after the end of the final treatment. In addition, no treatment-related abnormal clinical signs were observed in mice treated with any of the three different dosages of PR extract or CPA, with the exception of slight (1+) diarrhea signs, restrictedly and transiently detected 


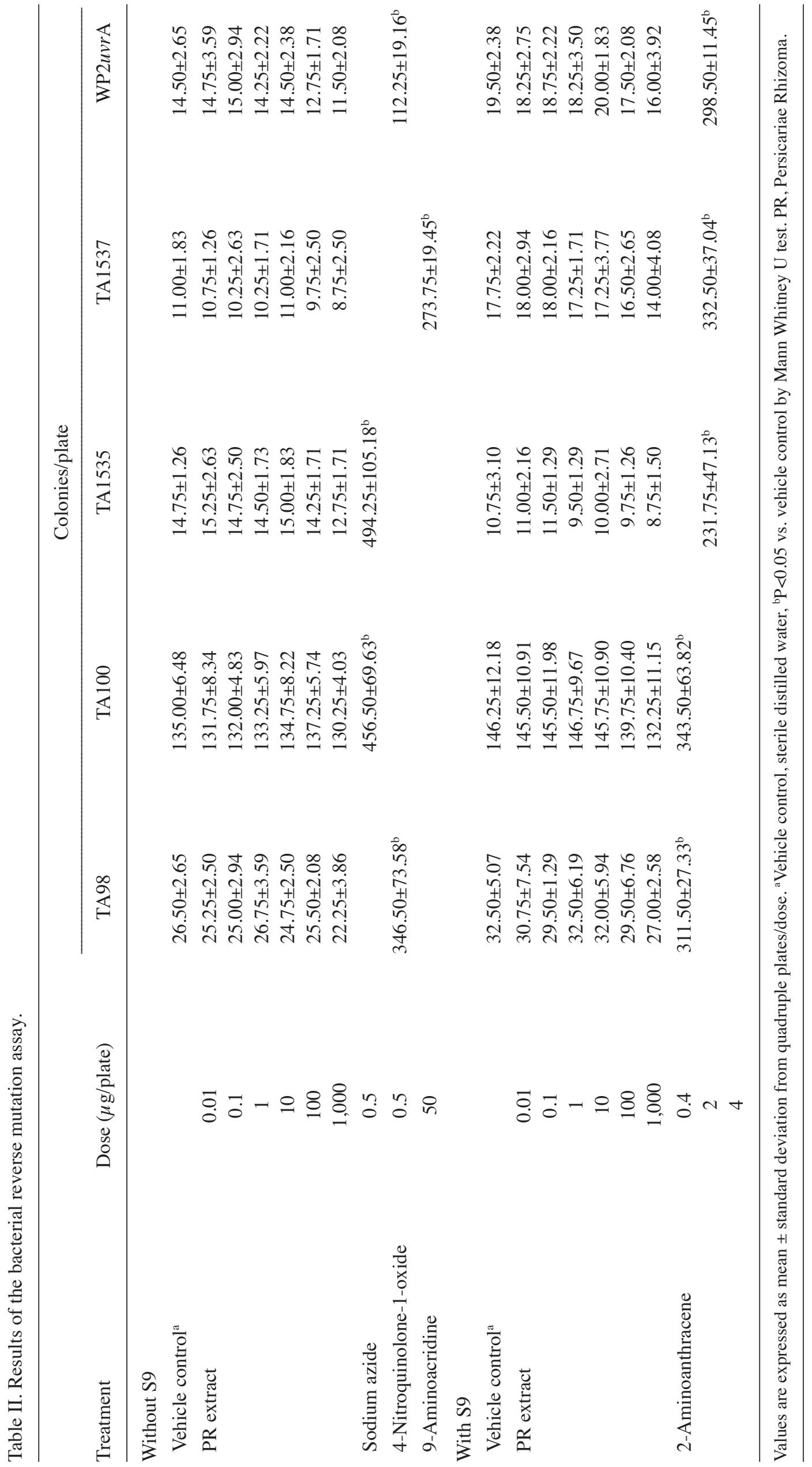


Table III. Results of preliminary range-finding tests for the chromosomal aberration assay.

\begin{tabular}{|c|c|c|c|}
\hline Treatment conditions & Dose $(\mu \mathrm{g} / \mathrm{ml})$ & Viable cells/flask & $\mathrm{RCC}^{\mathrm{a}}(\%)$ \\
\hline \multicolumn{4}{|c|}{ Treatment time $6 \mathrm{~h}$, recovery time $18 \mathrm{~h}$, with S9 } \\
\hline Vehicle control $^{\mathrm{b}}$ & & $11,871.25 \pm 1,034.27$ & 100.00 \\
\hline \multirow[t]{7}{*}{ PR extract } & 0.05 & $11,327.00 \pm 941.60$ & 95.42 \\
\hline & 0.5 & $12,054.25 \pm 1,123.84$ & 101.54 \\
\hline & 5 & $11,482.50 \pm 871.57$ & 96.73 \\
\hline & 50 & $11,931.50 \pm 568.58$ & 100.51 \\
\hline & 500 & $12,085.25 \pm 77.74$ & 101.80 \\
\hline & 1,000 & $10,641.25 \pm 691.62$ & 89.64 \\
\hline & 5,000 & $11,292.75 \pm 975.90$ & 95.13 \\
\hline Cyclophosphamide & 6 & $7,694.00 \pm 822.28$ & 64.81 \\
\hline \multicolumn{4}{|c|}{ Treatment time $6 \mathrm{~h}$, recovery time $18 \mathrm{~h}$, without S9 } \\
\hline Vehicle control $^{\mathrm{b}}$ & & $11,954.00 \pm 2,032.45$ & 100.00 \\
\hline \multirow[t]{7}{*}{ PR extract } & 0.05 & $11,469.00 \pm 852.76$ & 95.94 \\
\hline & 0.5 & $11,859.50 \pm 1,540.14$ & 99.21 \\
\hline & 5 & $11,902.75 \pm 1,909.86$ & 99.57 \\
\hline & 50 & $12,344.00 \pm 1,063.40$ & 103.26 \\
\hline & 500 & $11,473.75 \pm 895.79$ & 95.98 \\
\hline & 1,000 & $12,118.00 \pm 1,116.35$ & 101.37 \\
\hline & 5,000 & $10,836.00 \pm 436.41$ & 90.65 \\
\hline Ethylmethanesulfonate & 800 & $7,609.75 \pm 465.86$ & 63.66 \\
\hline \multicolumn{4}{|c|}{ Treatment time $24 \mathrm{~h}$, recovery time $0 \mathrm{~h}$, without $\mathrm{S} 9$} \\
\hline Vehicle control $^{\mathrm{b}}$ & & $11,220.75 \pm 978.78$ & 100.00 \\
\hline \multirow[t]{7}{*}{ PR extract } & 0.05 & $10,062.50 \pm 882.62$ & 89.68 \\
\hline & 0.5 & $11,643.25 \pm 1,526.13$ & 103.77 \\
\hline & 5 & $11,900.75 \pm 556.52$ & 106.06 \\
\hline & 50 & $11,304.50 \pm 2,231.19$ & 100.75 \\
\hline & 500 & $10,628.25 \pm 519.86$ & 94.63 \\
\hline & 1,000 & $11,380.00 \pm 2,133.52$ & 101.42 \\
\hline & 5,000 & $12,308.25 \pm 1,459.35$ & 109.69 \\
\hline Ethylmethanesulfonate & 600 & $7,019.75 \pm 1,146.26$ & 62.56 \\
\hline
\end{tabular}

Values of viable cells/flask are expressed as mean \pm standard deviation of two independent experiments. ${ }^{\text {aRCC}}$, relative cell count $(\%)=($ cell count of treated flask/cell count of control flask x 100. ${ }^{b}$ Vehicle control, sterile distilled water. PR, Persicariae Rhizoma.

in three $(3 / 10 ; 30 \%)$ mice treated with $2,000 \mathrm{mg} / \mathrm{kg}$ PR extract following the first administration, but not after the second treatment (Table V).

Significant $(\mathrm{P}<0.01)$ increases in the numbers of micronucleated bone marrow polychromatic erythrocytes (MNPCEs) detected among 2,000 PCEs were observed in the CPA-treated group as compared with the vehicle control group, but no significant changes in MNPCE numbers were observed for the mice in the 2,000, 1,000 and $500 \mathrm{mg} / \mathrm{kg}$ PR extract-treated mice as compared with the vehicle control group. Although the numbers of PCEs in the $70 \mathrm{mg} / \mathrm{kg}$ CPA-treated mice were significantly $(\mathrm{P}<0.01)$ decreased as compared with those in the vehicle control group, individual $\mathrm{PCE} /(\mathrm{PCE}+\mathrm{NCE})$ ratios were $>0.25$ in the present study. No significant or noteworthy changes in the PCE/(PCE + NCE) ratio were observed for the mice treated with $2,000,1,000$ and $500 \mathrm{mg} / \mathrm{kg}$ doses of
PR extract when compared with corresponding ratio in the vehicle control (Table V and Fig. 2).

\section{Discussion}

Genotoxicity tests carried out using bacterial, yeast and mammalian cells are aimed to assess whether substances will damage genetic material $(1,41)$. The primary use of in vitro testing is to evaluate whether chemical and physical agents, or environmental factors can damage genetic material. The information obtained from such tests can provide appropriate or sufficient control in the early development of vulnerable organisms to genotoxic substances $(2,3)$. The bacterial reverse mutation assay (Ames assay) is used to detect for gene mutation (42) and various bacterial strains can be used to compare different changes in the genetic material. This assay detects 


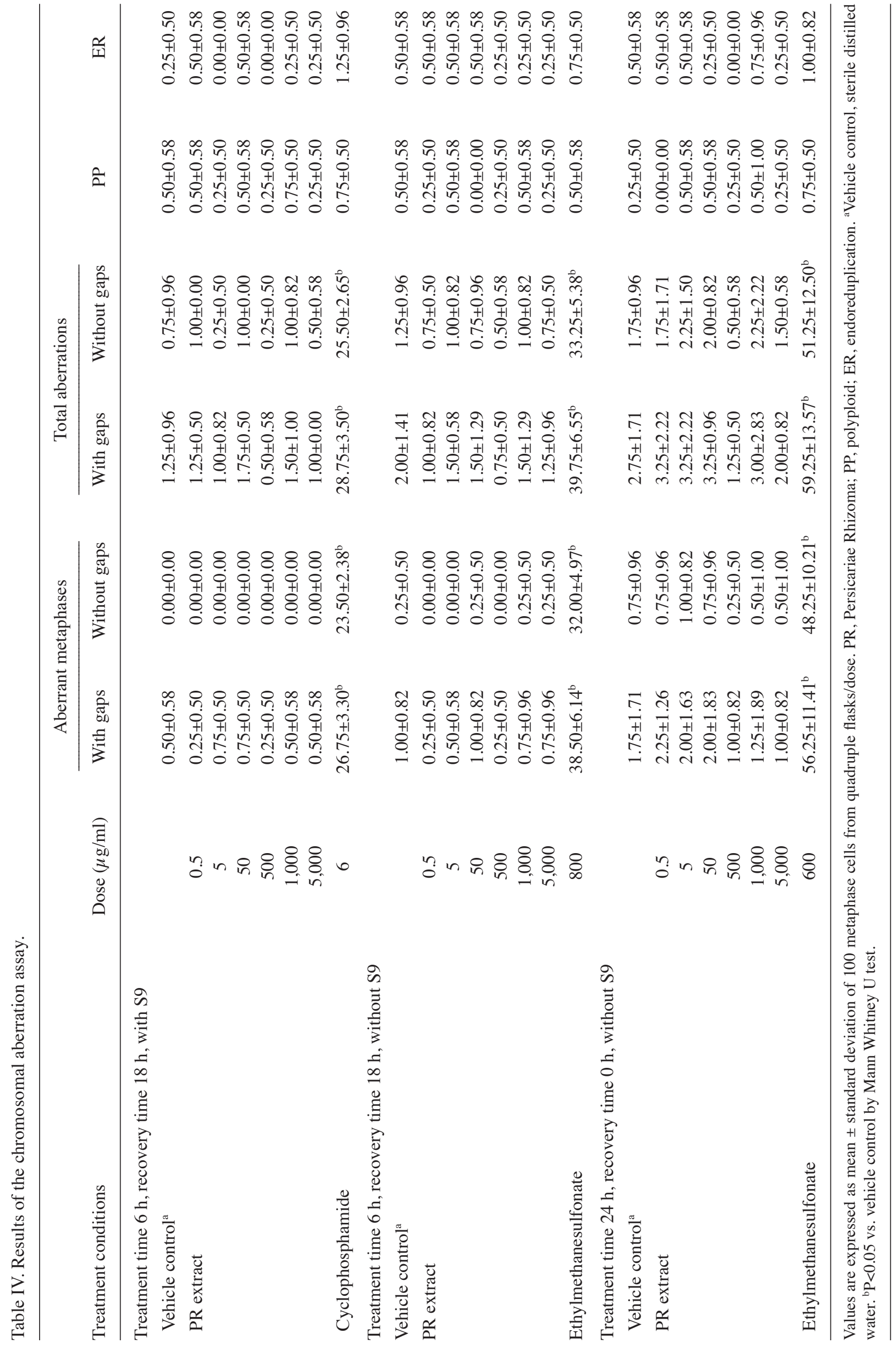


Table V. Results of micronucleus test.

\begin{tabular}{|c|c|c|c|c|c|c|c|}
\hline \multirow[b]{2}{*}{ Treatment } & \multirow{2}{*}{$\begin{array}{l}\text { Dose, } \\
\mathrm{mg} / \mathrm{kg}\end{array}$} & \multicolumn{2}{|c|}{ Body weight (g) } & \multirow{2}{*}{$\begin{array}{l}\text { No. of } \\
\text { MNPCE }^{a}\end{array}$} & \multirow[b]{2}{*}{$\mathrm{PCE} /(\mathrm{PCE}+\mathrm{NCE})^{\mathrm{b}}$} & \multirow{2}{*}{$\begin{array}{c}\text { Slight diarrhea, } \\
\text { n/total }\end{array}$} & \multirow{2}{*}{$\begin{array}{c}\text { Mortality } \\
\text { n/total }\end{array}$} \\
\hline & & First treatment & Sacrifice & & & & \\
\hline Vehicle control $^{\mathrm{c}}$ & & $31.73 \pm 0.88$ & $36.31 \pm 1.75$ & $1.30 \pm 1.42$ & $0.55 \pm 0.05$ & $0 / 10$ & $0 / 10$ \\
\hline \multirow[t]{3}{*}{ PR extract } & 2,000 & $31.88 \pm 1.03$ & $36.35 \pm 1.63$ & $0.90 \pm 0.88$ & $0.55 \pm 0.05$ & $3 / 10$ & $0 / 10$ \\
\hline & 1,000 & $31.78 \pm 1.55$ & $36.08 \pm 2.08$ & $1.10 \pm 0.99$ & $0.51 \pm 0.07$ & $0 / 10$ & $0 / 10$ \\
\hline & 500 & $31.60 \pm 1.17$ & $36.30 \pm 1.08$ & $0.40 \pm 0.52$ & $0.51 \pm 0.05$ & $0 / 10$ & $0 / 10$ \\
\hline Cyclophosphamide & 70 & $31.92 \pm 0.86$ & $36.08 \pm 0.97$ & $41.70 \pm 16.89^{\mathrm{e}}$ & $0.31 \pm 0.03^{\mathrm{d}}$ & $0 / 10$ & $0 / 10$ \\
\hline
\end{tabular}

Values are expressed as mean \pm standard deviation of 10 mice. PR, Persicariae Rhizoma; MNPCE, micronucleated bone marrow polychromatic erythrocyte; PCE, polychromatic erythrocyte; NCE, normochromatic erythrocyte. Animals were treated for 2 consecutive days (vehicle and PR extract) or once (cyclophosphamide) and sacrificed $24 \mathrm{~h}$ after the last dose. ${ }^{\mathrm{a}} \geq 2,000$ PCEs per animal were analyzed to determine the frequency of micronuclei. ${ }^{\text {b}}$ Cytotoxicity was assessed by scoring the number of PCEs and NCEs in at least the first 500 erythrocytes for each animal. ${ }^{c}$ Vehicle control, sterile distilled water. ${ }^{\mathrm{d}} \mathrm{P}<0.01$ vs. vehicle control by Scheffe's test. ${ }^{\mathrm{e}} \mathrm{P}<0.01$ vs. vehicle control by Mann Whitney U test.

specific genetic changes (mutations and cytogenetic abnormalities) and carcinogens; the types of mutations identified are frame shifts and base substitutions $(29,30)$. The chromosome aberration assay is used to identify structural and numerical chromosomal aberrations in mammalian cells (32). Genotoxic substance-induced aberrations include chromatid and chromosome gaps, chromosome breaks, chromatid deletions, fragmentation, translocation and complex rearrangements (33). Thus, an increase in the frequency of structural or numerical aberrations indicates that a genotoxic substance is generating clastogenic or aneugenic effects (43). The micronucleus test is used to indicate the potential of genotoxic agents to influence chromosomal structure or destroy the mitotic spindle that controls chromosome number. An increase in the frequency of MNPCEs is regarded as a positive result of induced chromosomal damage (44). When DNA fragments or whole chromosomes are not incorporated into the main nuclei during mitosis, micronuclei are formed as small satellite structure nuclei (40).

Indigo and indirubin, which is a 3,2-bisindole isomer of indigo, are representative bioactive anti-inflammatory and antioxidative natural dyes $(16,17)$, and herbal extracts containing indigo or their derivatives also have been shown to have potent antibacterial (19), antitumor (20), anti-inflammatory (21) and antioxidant (22) activities. However, certain synthetic colorants, if they enter into the human body in sufficient quantities, may be harmful (13). For example, mammalian intestinal microorganisms can generate degradation products such as aromatic amines from azo dyes under anerobic conditions. As these aromatic amines show potential mutagenic and carcinogenic effects, the use of azo dyes in foods has been limited (26). In addition, synthetic indigo of technical grade or $98 \%$ purity has exhibited mutagenic effects in the Salmonella/mammalian microsome assay (23) and also in the Ames test (25). PR is known to contain purple indirubin and blue indigo (15), and has been traditionally used as anti-inflammatory and detoxification agent in Korea (14). Until now, no preclinical studies of PR extracts containing indigo and indirubin, have been performed, to the best of our knowledge. Therefore, the genotoxicity of an aqueous extract of PR (yield $=12.0 \%$ ) containing indigo $(0.043 \%)$ and indirubin $(0.009 \%)$ was evaluated in the present study using a standard battery of various tests $(27,28)$ as part of a safety testing process aiming to clarify its clinical safety. The PR extract was not found to be genotoxic under the conditions of the reverse mutation assay, chromosomal aberration assay or mouse micronucleus assay conducted in this study.

In the reverse mutation assay, with or without $\mathrm{S} 9 \mathrm{mix}$ as a metabolic activation system, no increase in revertant colony number was detected. In addition, the PR extract did not induce chromosomal aberration in a short-term exposure test with the S9 mix or in the continuous ( $24 \mathrm{~h}$ ) test. Although slight signs of diarrhea were restrictedly and transiently detected in three $(3 / 10 ; 30 \%)$ mice treated with $2,000 \mathrm{mg} / \mathrm{kg}$ PR extract after the first administration, there were no significant increases of the frequency of MNPCEs at doses $\leq 2,000 \mathrm{mg} / \mathrm{kg}$.

Firstly, whether PR extract induces revertant colonies in four histidine auxotrophic strains of S. typhimurium and one tryptophan auxotrophic strain of E. coli was tested. There were no increases of the number of revertant colonies at any PR extract dose with or without the S9 mix metabolic activation system. These findings indicate a negative response to the PR extract in the bacterial reverse mutation assay. Secondly, to evaluate the mutagenicity of the PR extract, chromosome aberration testing was performed in cultured CHL cells. The number of aberrant metaphases did not increase in the PR extract-exposed groups at any dose or regardless of S9 mix, while a marked increase in the number of aberrant metaphases was detected in the positive controls. Thus, PR extract did not exhibit mutagenic potential in the chromosome aberration assay. Finally, to determine the mutagenic potential of the PR extract, a micronucleus assay was performed in male ICR mice. Although slight signs of diarrhea were restrictedly and transiently detected in three $(3 / 10 ; 30 \%)$ mice following the first administration of $2,000 \mathrm{mg} / \mathrm{kg}$ PR extract, no significant increases in the incidence of MNPCEs or the ratio of PCEs to total erythrocytes, which is an indicator of cytotoxicity (40), were observed following treatment with $\geq 2,000 \mathrm{mg} / \mathrm{kg}$ PR extract. These results of the micronucleus test indicate that the PR extract was not mutagenic. In vivo micronucleus testing has been widely used to detect genotoxicity due to its simplicity and efficacy. Furthermore, if the micronucleus assay 
A

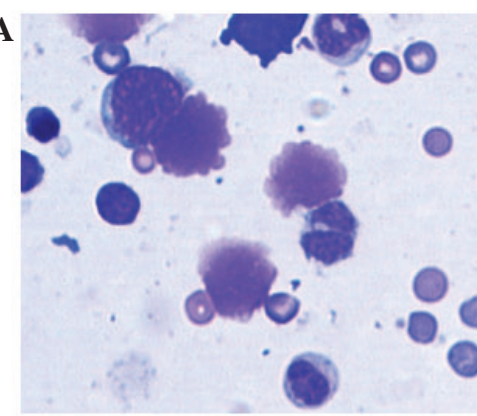

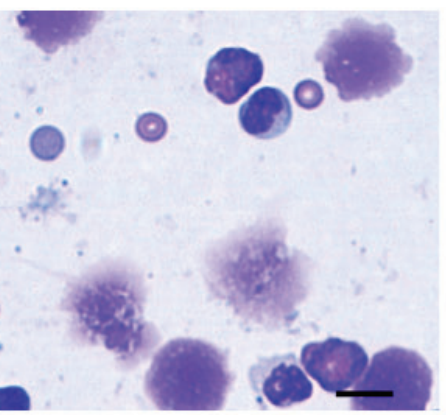

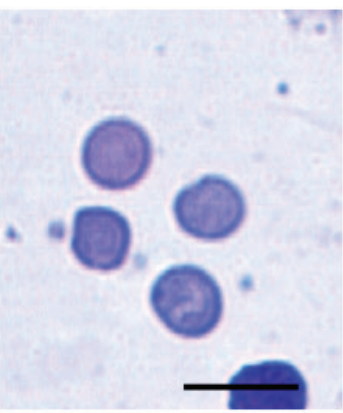

B

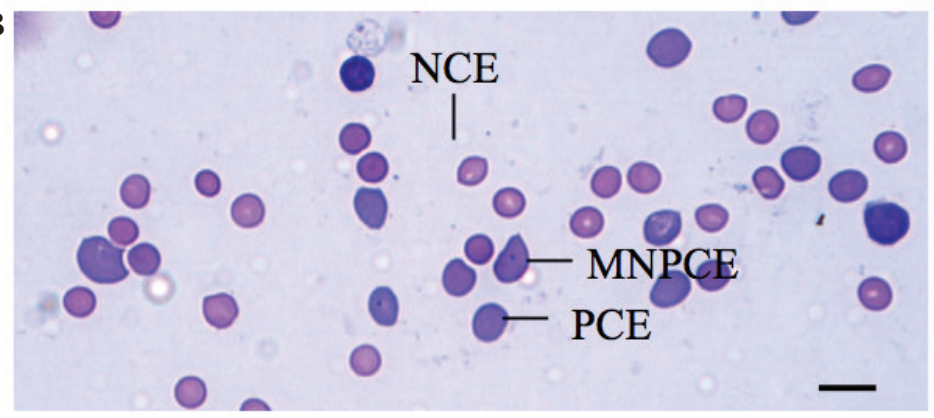

C
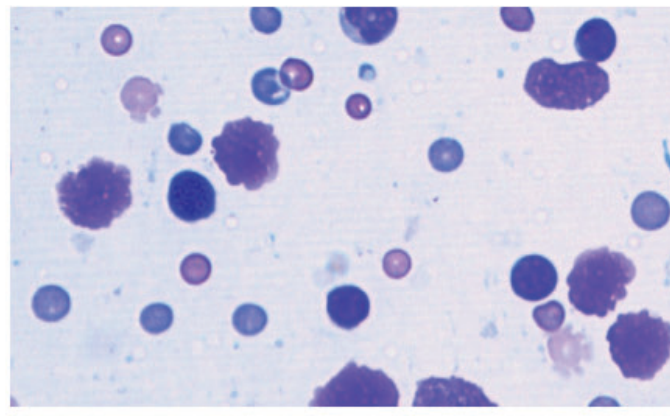

(
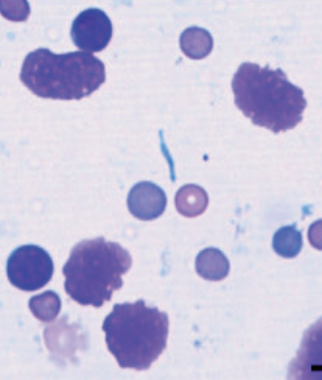

-
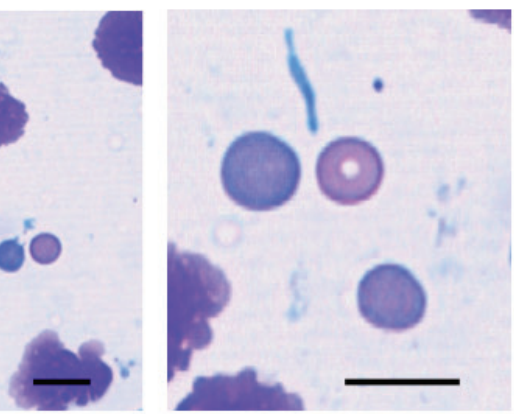

D
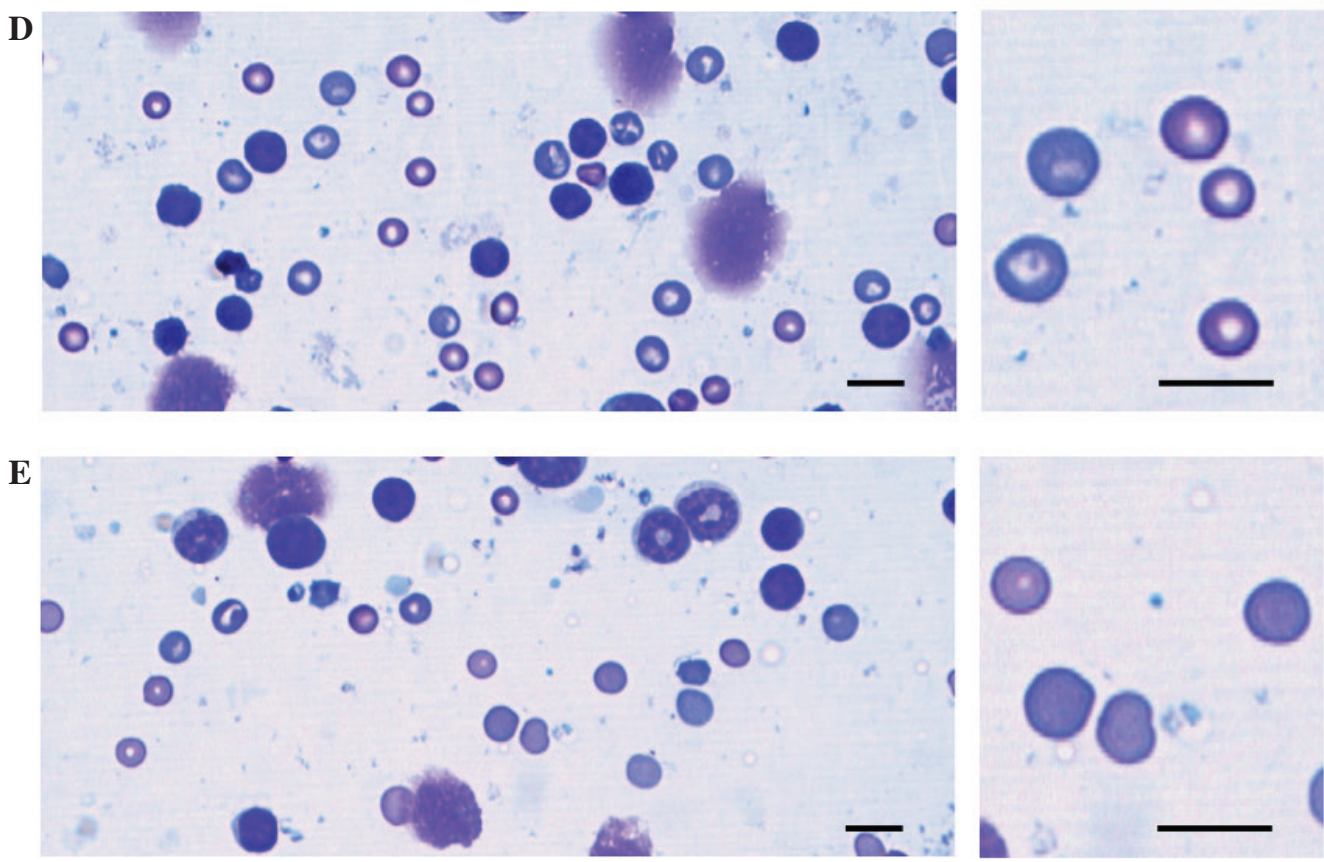

Figure 2. Representative cytology of bone marrow cell smears of mice treated with (A) vehicle, (B) CPA, (C) 2,000 mg/kg PR extract, (D) $1,000 \mathrm{mg} / \mathrm{kg}$ PRextract and (E) $500 \mathrm{mg} / \mathrm{kg}$ PR extract. In the prepared bone marrow cell smears, PCEs, NCEs and MNPCEs were counted on the basis of morphology. NCEs containing nuclei were not calculated. Significant $(\mathrm{P}<0.01)$ increases of the numbers of MNPCEs among 2,000 PCEs were detected in the CPA group as compared with the vehicle control, but no notable changes in MNPCE numbers were observed for mice treated with any of the three doses of PR extract when compared with the vehicle control. Although PCE numbers in the $70 \mathrm{mg} / \mathrm{kg}$ CPA-treated mice were significantly $(\mathrm{P}<0.01)$ decreased as compared with the vehicle control, individual PCE/(PCE + NCE) ratios were $>0.25$. No significant changes on the PCE/(PCE + NCE) ratio were observed for mice treated with any of the three PR extract doses as compared with the vehicle control. CPA, cyclophosphamide; PR, Persicariae Rhizoma; PCE, polychromatic erythrocyte; NCE, normochromatic erythrocyte; MNPCE, micronucleated bone marrow polychromatic erythrocytes. Scale bar, $5 \mu \mathrm{m}$. 
is conducted in combination with other cytogenetic assays, this assay has greater relevance in the evaluation of the mutagenicity and carcinogenicity of test materials (40). All mice used in this study, including CPA-treated mice, were found to have normal body weights and weight gains throughout the experimental testing period, in comparison with age-matched normal reference mice (45), and no mortalities were recorded.

In summary, the results of the present study indicate that the aqueous PR extract should be safe to use, particularly if it is consumed in small amounts compared with the doses used in the genotoxicity tests. Furthermore, these results suggest that PR extract may be a useful bioactive agent following further toxicity evaluation.

\section{Acknowledgements}

This study was supported by the National Research Foundation of Korea (NRF) funded by the Korean government (Ministry of Science, ICT and Future Planning; grant no. 2011-0030124) and as a Basic Science Research Program by the Ministry of Education, Science and Technology (grant no. NRF-2012R1A1A2043886).

\section{References}

1. Keong LC and Halim AS: In vitro models in biocompatibility assessment for biomedical-grade chitosan derivatives in wound management. Int J Mol Sci 10: 1300-1313, 2009.

2. Mei N, Guo L, Fu PP, Fuscoe JC, Luan Y and Chen T: Metabolism, genotoxicity, and carcinogenicity of comfrey. J Toxicol Environ Health B Crit Rev 13: 509-526, 2010.

3. Momi N, Kaur S, Ponnusamy MP, Kumar S, Wittel UA and Batra SK: Interplay between smoking-induced genotoxicity and altered signaling in pancreatic carcinogenesis. Carcinogenesis 33: 1617-1628, 2012.

4. DeMarini DM: Genotoxicity biomarkers associated with exposure to traffic and near-road atmospheres: A review. Mutagenesis 28: 485-505, 2013.

5. Burlinson B: The in vitro and in vivo comet assays. In: Genetic Toxicology. Parry JM and Parry EM (eds). Springer, New York, NY, pp143-163, 2012.

6. Magdolenova Z, Collins A, Kumar A, Dhawan A, Stone V and Dusinska M: Mechanisms of genotoxicity. A review of in vitro and in vivo studies with engineered nanoparticles. Nanotoxicology 8: 233-278, 2014

7. Chen T, Mei N and Fu PP: Genotoxicity of pyrrolizidine alkaloids. J Appl Toxicol 30: 183-196, 2010.

8. Jeong YT, Kim YD, Jung YM, Park DC, Lee DS, Ku SK, Li X, $\mathrm{Lu} \mathrm{Y,} \mathrm{Chao} \mathrm{GH,} \mathrm{Kim} \mathrm{KJ,} \mathrm{et} \mathrm{al:} \mathrm{Low} \mathrm{molecular} \mathrm{weight} \mathrm{fucoidan}$ improves endoplasmic reticulum stress-reduced insulin sensitivity through AMP-activated protein kinase activation in L6 myotubes and restores lipid homeostasis in a mouse model of type 2 diabetes. Mol Pharmacol 84: 147-157, 2013.

9. Noh JR, Kim YH, Gang GT, Hwang JH, Kim SK, Ryu SY, Kim YS, Lee HS and Lee CH: Hepatoprotective effect of Platycodon grandiflorum against chronic ethanol-induced oxidative stress in C57BL/6 mice. Ann Nutr Metab 58: 224-231, 2011.

10. Aeschbacher HU: Genetic toxicology of food products. In: Mutation and the Environment: Environmental Genotoxicity, Risk and Modulation, Part E. Mendelsohn ML and Albertini RJ, (eds). Wiley-Liss, Inc., New York, NY, pp117-126, 1990.

11. Williams GM: Food-borne carcinogens. In: Genetic Toxicology of the Diet. Knudsen I (ed). A.R. Liss, New York, NY, pp3-81, 1986.

12. Sugimura T, Sato S, Ohgaki H, Takayama S, Nagao $M$ and Wakabayashi K: Mutagens and carcinogens in cooked food. In: Genetic and Toxicology of the Diet. Knudsen I (ed.) A.R. Liss, New York, NY, pp105-107, 1986.

13. Sarıkaya R, Selvi M and Erkoç F: Evaluation of potential genotoxicity of five food dyes using the somatic mutation and recombination test. Chemosphere 88: 974-979, 2012.
14. Woo YM, Kim AJ, Kim JY and Lee CH: Tyrosinase inhibitory compounds isolated from Persicaria tinctoria flower. J Appl Biol Chem 54, 2011.

15. Kim SJ, Ko JH, Park SH, Kim MS and Kim KS: Preparation method of indigo standard solution and variation of indigo contents in blue dye extract from breeding lines of Persicaria tinctoria H. Gross. Korean J Medicinal Crop Sci 21: 213-219, 2013.

16. Xiao Z, Hao Y, Liu B and Qian L: Indirubin and meisoindigo in the treatment of chronic myelogenous leukemia in China. Leuk Lymphoma 43: 1763-1768, 2002.

17. Mok CK, Kang SS, Chan RW, Yue PY, Mak NK, Poon LL, Wong RN, Peiris JS and Chan MC: Anti-inflammatory and antiviral effects of indirubin derivatives in influenza A (H5N1) virus infected primary human peripheral blood-derived macrophages and alveolar epithelial cells. Antiviral Res 106: 95-104, 2014.

18. Hoessel R, Leclerc S, Endicott JA, Nobel ME, Lawrie A, Tunnah P, Leost M, Damiens E, Marie D, Marko D, et al: Indirubin, the active constituent of a Chinese antileukaemia medicine, inhibits cyclin-dependent kinases. Nat Cell Biol 1: 60-67, 1999.

19. Kataoka M, Hirata K, Kunikata T, Ushio S, Iwaki K, Ohashi K, Ikeda M and Kurimoto M: Antibacterial action of tryptanthrin and kaempferol, isolated from the indigo plant (Polygonum tinctorium Lour.), against Helicobacter pylori-infected mongolian gerbils. J Gastroenterol 36: 5-9, 2001.

20. Jang HG, Heo BG, Park YS, Namiesnik J, Barasch D, Katrich E, Vearasilp K, Trakhtenberg S and Gorinstein S: Chemical composition, antioxidant and anticancer effects of the seeds and leaves of Indigo (Polygonum tinctorium Ait) plant. Appl Biochem Biotechnol 167: 1986-2004, 2012.

21. Lin YK, Leu YL, Huang TH, Wu YH, Chung PJ, Su Pang JH and Hwang TL: Anti-inflammatory effects of the extract of indigo naturalis in human neutrophils. J Ethnopharmacol 125: 51-58, 2009.

22. Lin YK, Chen HW, Yang SH, Leu YL, Huang YH and Yen HC: Protective effect of indigo naturalis extract against oxidative stress in cultured human keratinocytes. J Ethnopharmacol 139: 893-896, 2012

23. Jongen WM and Alink GM: Enzyme-mediated mutagenicity in Salmonella typhimurium of contaminants of synthetic indigo products. Food Chem Toxicol 20: 917-920, 1982.

24. Jongen WM: Metabolic activation of promutagenic factors in synthetic indigo by mammalian microsomes. Carcinogenesis 3 : 1321-1323, 1982.

25. Rannug U, Bramstedt $\mathrm{H}$ and Nilsson U: The presence of genotoxic and bioactive components in indigo dyed fabrics - a possible health risk? Mutat Res 282: 219-225, 1992.

26. Ashkenazi P, Yarnitzky C and Cais M: Determination of synthetic food colours by means of a novel sample preparation system. Anal Chim Acta 248: 289-299, 1991.

27. Seo JY, Park MY, Jung TY, Choi HY, Kim JD, Lee HS and $\mathrm{Ku}$ SK: Genotoxicity testing of aqueous extracts of Mahwangyounpae-tang, a polyherbal formula. Food Chem Toxicol 46: 3827-3831, 2008.

28. Song MY, Ku SK and Han JS: Genotoxicity testing of low molecular weight fucoidan from brown seaweeds. Food Chem Toxicol 50: 790-796, 2012.

29. Ames BN, McCann J and Yamasaki E: Methods for detecting carcinogens and mutagens with the Salmonella/mammalian-microsome mutagenicity test. Mutat Res 31: 347-364, 1975.

30. Green $\mathrm{MH}$ and Muriel WJ: Mutagen testing using $\mathrm{TRP}^{+}$reversion in Escherichia coli. Mutat Res 38: 3-32, 1976.

31. Maron DM and Ames BN: Revised methods for the Salmonella mutagenicity test. Mutat Res 113: 173-215, 1983.

32. Dean BJ and Danford N: Assays for the detection of chemically-induced chromosome damage in cultured mammalian cells. In: Mutagenicity Testing - A Practical Approach. Venitt S and Parry JM (eds) IRL Press, Oxford, pp187-232, 1984.

33. Koyama H, Utakoji T and Ono T: A new cell line derived from newborn Chinese hamster lung tissue. Gan 61: 161-167, 1970.

34. Evans H: Cytological methods for detecting chemical mutagens. In: Chemical Mutagens, Principles and Methods for their Detection. Vol 4. Hollaender A (ed). Plenum Press, New York, NY, pp1-29, 1976.

35. Flecknell P (ed): Laboratory Animal Anaesthesia. 3rd edition. Elsevier Academic Press, New York, NY, 2009.

36. Dourish CT: Effects of drugs on spontaneous motor activity. In: Experimental Psychopharmacology. Greenshaw AJ and Dourish CT (eds). Humana Press, Clifton, NJ, pp153-176, 1987. 
37. Choi JS, Kim JW, Kim KY, Ku SK and Sohn JH: Single-dose oral toxicity of fermented rice extracts (FREs): A 14-day observation. Pak J Pharm Sci 27: 129-137, 2014.

38. Schmid W: The micronucleus test. Mutat Res 31: 9-15, 1975.

39. Schimd W: The micronucleus test for cytogenetic analysis. In: Chemical Mutagens. Principles and Methods for their Detection. Vol 4. Hollaender A (ed). Plenum Press, New York, pp31-53, 1976.

40. Heddle JA, Stuart E and Salamone MF: The bone marrow micronucleus test. In: Handbook of Mutagenicity Test Procedures. 2nd edition. Kilbey BJ, Legator M, Nicholson W and Ramel C (eds). Elsevier, Amsterdam, pp441-457, 1984.

41. Scholz S, Fischer S, Gündel U, Küster E, Luckenbach T and Voelker D: The zebrafish embryo model in environmental risk assessment-applications beyond acute toxicity testing. Environ Sci Pollut Res Int 15: 394-404, 2008.
42. Mortelmans K and Zeiger E: The ames Salmonella/microsome mutagenicity assay. Mutat Res 455: 29-60, 2000.

43. Speit G, Kühner S, Linsenmeyer R and Schütz P: Does formaldehyde induce aneuploidy? Mutagenesis 26: 805-811, 2011.

44. Chung IK, Cheon WH and Ku SK: Micronucleus test of Picrorrhiza Rhizoma aqueous extract in bone marrow cells of male ICR mice. Toxicol Res 27: 119-123, 2011.

45. Tajima Y and Horiuchi S: Biological Reference Data Book on Experimental Animals. Soft Science, Tokyo, pp2-3, 1989 (In Japanese). 